\title{
O ofício de parteira no Rio de Janeiro imperial
}

\author{
Midwifery in Imperial Rio de Janeiro \\ Giselle Machado Barbosa* \\ Tânia Salgado Pimenta ${ }^{* *}$
}

\begin{abstract}
Resumo
Durante o século XIX, no Brasil, observou-se um processo de institucionalização da medicina com implicações nos diferentes ofícios relacionados às artes de curar. As parteiras tradicionais passaram a ser desqualificadas, mas aquelas que tivessem formação acadêmica, nos cursos oferecidos na faculdade de medicina do Rio e da Bahia ou no exterior, teriam espaço legal para atuarem dentro de certos limites. A atuação crescente das parteiras diplomadas, contudo, não significou o desaparecimento das parteiras tradicionais. Percebemos a coexistência de diversos perfis de mulheres exercendo o ofício. Nesse artigo, pretendemos analisar a atuação de parteiras atentando para o seu cotidiano e as redes construídas entre elas e com os médicos. Para tanto, procuramos conhecer melhor as seguintes questões: onde, com quem e para que público essas mulheres trabalhavam. Destacamos a interação entre as parteiras, sobretudo as com formação acadêmica, verificada através do compartilhamento de endereços. As principais fontes utilizadas são os anúncios de parteiras publicados no Almanaque Laemmert (anual) e n'O Diário do Rio de Janeiro, abrangendo o período de 1822 a 1889.
\end{abstract}

Palavras-chave: Parteira; Parto; Maternidade; Rio de Janeiro

\begin{abstract}
There was a process of institutionalization of medicine with implications in different crafts related to the healing arts during the nineteenth century, in Brazil. Midwives were disqualified, but those who had academic training in the Faculty of Medicine of Rio de Janeiro and of Bahia or abroad, would have legal space to work within certain limits. The increasing role of midwives, however, did not mean the disappearance of traditional birth attendants. We observe the coexistence of different profiles of women exercising their craft. In this article, we analyze the performance of midwives paying attention to
\end{abstract}

\footnotetext{
*Mestre pelo Programa de Pós-Graduação em História das Ciências e da Saúde (PPGHCS) da Casa de Oswaldo Cruz (COC) - FIOCRUZ. E-mail: gismbarbosa@gmail.com

** Doutora em História pela UNICAMP; professora do Programa de Pós-Graduação em História das Ciências e da Saúde da FIOCRUZ.E-mail: taniacoc@gmail.com
} 
your daily life and the networks built between them and doctors. Therefore, we seek to understand the following questions: where, with whom and for what public these women worked. We highlight the interaction between midwives, especially with academic training, verified through the address sharing. The main sources used are the midwives of notices published in Almanaque Laemmert (annual) and Diário do Rio de Janeiro, covering the period 1822-1889.

Keywords: Midwives, Births, Maternity, Rio de Janeiro

\section{Introdução}

Durante o século XIX, no Brasil, observou-se um processo de institucionalização da medicina com implicações nos diferentes ofícios relacionados às artes de curar. No final da década de 1820 e início da década de 1830, foram criadas as faculdades de medicina do Rio de Janeiro e da Bahia (1832), a Sociedade de Medicina do Rio de Janeiro (1829), posteriormente Academia Imperial de Medicina (1835), e diversos periódicos médicos especializados. Curandeiros foram desautorizados a exercer suas atividades terapêuticas, enquanto sangradores passaram a ser desqualificados, permanecendo com licença aqueles que a obtiveram antes da lei de criação das Faculdades de Medicina do Rio de Janeiro e da Bahia (lei de 3/10/1832). As parteiras, por sua vez, continuaram a ter espaço legal para atuarem dentro de certos limites, sendo criado um curso, cujo objetivo era ensiná-las o ofício a partir de pressupostos da medicina acadêmica. Aquelas formadas no exterior deveriam validar o seu diploma na faculdade de medicina.

As parteiras, portanto, poderiam continuar a partejar desde que subordinadas à autoridade dos médicos acadêmicos. A história do exercício da arte de partejar no Brasil, no entanto, não é linear e simples. É necessário considerar os contextos e, sobretudo, atentar para o fato de que as mulheres que auxiliam outras a darem a luz não constituíam um grupo homogêneo. Nesse sentido, nossa análise será focada nas parteiras formadas em cursos acadêmicos, cujos diplomas foram concedidos ou validados pela Faculdade de Medicina do Rio de Janeiro, que atuaram na corte do Rio de Janeiro e que anunciaram seus serviços entre 1832 e 1889. Constituíam um novo perfil de parteira, sendo muitas vezes estrangeiras, sem laços na cidade e precisando se fazer conhecer. Através dos anúncios, torna-se possível nos aproximarmos um pouco mais do universo dessas mulheres que passaram a ser importantes com 
a transformação da cidade do Rio de Janeiro. Essas mulheres responderam e ajudaram a criar uma demanda por partos não domiciliares naquela sociedade. Nesse artigo, pretendemos analisar a atuação de parteiras atentando para o seu cotidiano e as redes construídas entre elas e com os médicos. Para tanto, procuramos conhecer melhor as seguintes questões: onde, com quem e para que público essas mulheres trabalhavam.

Destacamos, contudo, que as parteiras tradicionais que atuaram nos limites de uma comunidade específica, aquelas que se restringiram a ajudar familiares e pessoas próximas ou ainda as que exerciam o ofício sem legalizar sua prática existiram durante todo o século XIX. A relação com os médicos acadêmicos, nesse caso, era mais simples. Eram desqualificadas e desautorizadas e, portanto, deveriam ser impedidas de exercer a atividade. 0 processo de desqualificação das parteiras não formadas na academia ocorreu ao mesmo tempo em que se procurava submeter as parteiras diplomadas aos preceitos da medicina. Buscava-se a incorporação efetiva da assistência ao parto aos domínios médicos, junto com a subordinação das parteiras aos acadêmicos. ${ }^{1}$ Essas mulheres, parteiras, deveriam ser formadas e avaliadas pelos homens, médicos.

Esse processo de desqualificação pelo discurso médico dos saberes e práticas populares das parteiras pode ser observado em outros contextos como, por exemplo, no México, onde as parteiras apresentaram resistências, não permitindo que seu ofício fosse submetido às imposições de médicos e de instituições, apesar do esforço em institucionalizar o seu trabalho. ${ }^{2}$ Outro importante estudo sobre o contexto mexicano aponta para a criação da carreira de parteira como meio de eliminar as parteiras tradicionais. A parteira como profissional foi criada por ser uma atividade necessária à profissão médica, mantendo-se subordinada a esta. Houve ainda, um processo

\footnotetext{
${ }^{1}$ Sobre esse processo em outros contextos, ver, por exemplo, para México: ZOLLA, Carlos e CARRILLO, Ana Maria. Mujeres, saberes médicos e institucionalización. In: FIGUEROA, Juan Guillermo (Org.). La condición de la mujer en el espacio de la salud. México: El Colegio de México, 1998. pp. 167-198; para Espanha ORTIZ e MARTÍNEZ PADILLA. How to be a midwife in late nineteenth century Spain. In: MARLAND, Hilary e RAFFERTY, Anne Marie. Midwives, society and childbirth - debates and controversies in the modern period. Nova Iorque: Routledge, 1997 pp.61-80; e outros países europeus: MARLAND, Hilary. Midwives, society and childbirth - debates and controversies in the modern period. Londres e Nova Iorque: Routledge, 1997. MARLAND, Hilary. The art of midwifery - early modern midwives in Europe, Londres e Nova Iorque: Routledge, 1993; para EUA, QUIROGA, Virginia, Poor mothers and babies - a social history of childbirth and child care hospitals in Nineteenth-Century New York City. Nova Iorque e Londres: Garland Publishing, 1989 e McGREGOR, Deborah. From midwives to medicine - the birth of American gynecology. New Brunswick, Nova Jersey, Londres: Rutgers University Press, 1998.
}

${ }^{2}$ ROBLES, L. C.D. e SANDOVAL, L. O. Las parteras de Guadalajara (México) en el siglo XIX: el despojo de su arte. Dynamis, v.27, 2007, p. 237-261. 
no qual os médicos buscaram desqualificar e combater as parteiras por elas supostamente invadirem o campo de atuação deles. ${ }^{3}$

Em relação ao Brasil, apontamos algumas pesquisas como a de Pimenta, que investigou as artes de curar regulamentadas pela Fisicatura-mor entre 1808 e 1828, incluindo as parteiras licenciadas pelo órgão. ${ }^{4}$ Maria Renilda Barreto também contempla as parteiras licenciadas na Bahia, investigando sobre as parteiras leigas e licenciadas naquela província, na qual pesquisou tanto os registros de óbito e batismo como os registros de licença contidos nos livros da Fisicatura-mor. ${ }^{5}$ Apesar de seu recorte espacial ser a Bahia, ela analisa a história da parturição e as formas como ocorriam os exames, aplicados a todo o império incluindo Portugal enquanto metrópole.

A obra de Maria Lucia Mott destaca-se entre as referências sobre a história das parteiras no Brasil do século XIX. No artigo, Parteiras: 0 outro lado da profissão, Mott analisou a formação, a fiscalização, o perfil social e as técnicas utilizadas pelas parteiras. O seu enfoque nesse trabalho foram os conflitos e disputas vividos pelas parteiras. ${ }^{6}$ Foram pesquisados anúncios, classificados, cartas de leitores e reportagens de jornais e almanaques, algumas das fontes que também pesquisamos no nosso trabalho. Seu recorte temporal compreende os anos 1830 a 1930, a partir dos quais realiza uma discussão sobre a prática da parturição ao longo do século XIX. De acordo com Mott, as parteiras poderiam ser classificadas em dois tipos: as ocasionais e as de ofício. As primeiras faziam alguns partos ao longo da vida, enquanto as segundas, apesar de leigas, tinham maior experiência e capacidade em lidar com partos complicados. Além disso, a autora também atenta para a disputa entre as parteiras leigas e as diplomadas.

Mott ressalta a importância dos periódicos na vida profissional das parteiras diplomadas, como o meio pelo qual elas divulgavam os seus trabalhos e conseguiam clientes. Sobretudo as parteiras diplomadas vindas de Paris que concorriam com as não formadas, que já possuíam clientela na cidade. Sobre a prática de partos em si, Mott salienta que nas primeiras décadas do século XIX, ocorria na casa da parturiente e, somente em casos extremos,

\footnotetext{
${ }^{3}$ CARRILlO, op. cit., p. 175.

${ }^{4}$ PIMENTA, Tânia Salgado. Artes de curar. Um estudo a partir dos documentos da Fisicatura-mor no Brasil no começo do século XIX. Dissertação de mestrado. Campinas: UNICAMP, 1997.

${ }^{5}$ BARRETO, Maria Renilda Nery. Assistência do nascimento na Bahia oitocentista. História, Ciências, Saúde - Manguinhos, Rio de Janeiro, v. 15, n. 4, 2008.

${ }^{6}$ MOTT, Maria Lucia. Parteiras: O outro lado da profissão. Gênero: Núcleo Transdisciplinar de Estudos de Gênero, Niterói, v. 6, n. 1, 2005. p. 117-140.
} 
difíceis, as mulheres recorriam à enfermaria das Santas Casas. Por ser um acontecimento no qual se agregavam as mulheres da família e vizinhas, as parturientes nomeavam a parteira como "comadre", demonstrando que havia laços de respeito e afetividade entre essas mulheres. ${ }^{7}$ Por outro lado, em alguns de seus trabalhos, Mott chama a atenção para a rivalidade e disputa entre as parteiras, pois a concorrência entre elas foi aumentando à medida que as parteiras estrangeiras precisavam se estabelecer na cidade e adquirir nova clientela. Como estratégia para atrair "freguesia", essas madames recém-chegadas ao Rio de Janeiro anunciavam nos jornais. ${ }^{8}$

Em tese de doutorado, Brenes apresenta a questão do conflito entre profissionais na França e seus desdobramentos na cidade do Rio de Janeiro. Esses conflitos se deslocaram tanto devido à chegada de parteiras francesas, como a partir do modelo francês de ensino que inspirou a escola de partos no Brasil. Sobre as imigrantes que aqui se instalaram para exercer sua arte, a autora contabilizou um total de 167 parteiras entre 1844 e 1913..$^{9}$ Além disso, seu estudo lança um olhar sobre o perfil dessas mulheres através do Almanaque Laemmert, também estudado em nosso trabalho. Para Brenes, as mulheres estrangeiras presentes no Brasil eram, na maioria, maduras e independentes, viúvas, sozinhas, com filho para criar, sendo a maior parte pobre e, portanto, utilizavam a arte como alternativa para sobreviver. ${ }^{10} \mathrm{~A}$ autora se dedicou às parteiras francesas no Brasil em seus estudos, buscando compreender possíveis associações com a prática delas e a formação em cursos de parto ou maternidades na França.

As relações conflituosas entre médicos e parteiras ou mesmo entre as parteiras formadas e as práticas constitui um ponto que vem sendo explorado pelos estudos acerca do tema e sobre o qual há concordância na historiografia. A construção de redes entre as parteiras e o cotidiano dessas mulheres têm sido apontados, mas consideramos importante buscar aprofundar esses aspectos. Nesse artigo, pretendemos contribuir para compreender melhor a atuação cotidiana daquelas parteiras que começaram a atuar de forma mais expressiva no Rio de Janeiro de meados do Oitocentos.

\footnotetext{
${ }^{7}$ Ibidem, p.119.

${ }^{8}$ Ibidem, p. 119.

${ }^{9}$ BRENES, Anayansi Correa. Um olhar brasileiro sobre o caso de Paris: 0 conflito parteiras-parteiros e seus desdobramentos no Rio de Janeiro, século XIX. Tese de Doutorado. Niterói: UFF, 1996, p. 25.

${ }^{10}$ BRENES, op. cit., p. 217.
} 
As principais fontes utilizadas são os anúncios de parteiras publicados no Almanaque Laemmert ${ }^{11}$ (anual). Os dados sistematizados foram cruzados com as informações obtidas nos anúncios de 0 Diário do Rio de Janeiro, 0 Paquete do Rio, Correio Mercantil e O Despertador. Tais periódicos se encontram digitalizados, alguns na íntegra e outros com boa parte do seu material, no site da Hemeroteca Digital da Biblioteca Nacional, no qual foi feita buscas por palavras-chave..$^{12}$ Ressalta-se que os anúncios de parteiras no Diário se estenderam até 1876 e não em 1878, último ano em que o periódico esteve em circulação. Além disso, esses são os dados relacionados exclusivamente aos anúncios de parteiras, não levando em conta outros tipos como de casas de saúde, médicos parteiros, notas críticas, notícias e folhetins. Observando os números, pode-se verificar que há poucos anúncios por ano no Diário do Rio de Janeiro se comparado ao total encontrado no Almanaque Laemmert no mesmo espaço de tempo. É possível observar, ainda, um aumento no número de propagandas no Diário a partir de 1858, com destaque para os anos de 1860 com 40 anúncios, 1864 com 49 e 1869 com 31 . Ainda que tivessem esses picos, foram constatados intervalos em que não houve uma única propaganda de parteira, ou, ainda, menos de 10 no ano. Já no Almanaque, houve um aumento progressivo a partir de 1845, com exceção de $1846 .{ }^{13}$ Entre 1847 e 1889 não houve menos de 10 anúncios por ano e na maior parte dos anos manteve-se em torno de 20 anúncios por ano, com poucas variações.

Assim, entre 1844 e 1889 foram publicados 806 anúncios de parteiras no Almanaque Laemmert, correspondendo a 85 parteiras. No Diário do Rio de Janeiro, 37 parteiras publicaram, ao todo, 235 anúncios entre 1822 e 1878 . A importância desses dois periódicos se dá pelo fato de a maioria das parteiras ter anunciado com frequência. Nas páginas do Diário e Almanaque, as parteiras repetiam os textos dos anúncios, publicando diversas vezes a mesma informação. Algumas apresentaram a sua formação ou atuação, sendo recorrentes as que se diziam formadas pela Faculdade de Paris ou discípulas da maternidade de Paris. Boa parte também afirmou ter sido aprovada ou ter seu diploma reconhecido pela Faculdade de Medicina do Rio de Janeiro. Nesse trabalho, consideramos como parteiras com formação acadêmica aquelas que

\footnotetext{
${ }^{11}$ Periódico de publicação anual. O acervo consultado é composto pelas edições de 1844 a 1889 no site: http://objdigital.bn.br/acervo_digital/div_periodicos/almanak/almanak_djvu.htm

${ }^{12}$ Pode ser acessado através do site: http://objdigital.bn.br/acervo_digital/div_periodicos/almanak/ almanak.htm

${ }^{13} \mathrm{~A}$ página referente às parteiras no Almanaque Laemmert não está disponibilizada nas versões eletrônica e de microfilme e, portanto, sem acesso. Informação retirada do site de consulta em julho de 2016.
} 
se identificaram como tal nos anúncios, somando 31. As estrangeiras eram, na maior parte, de origem francesa, tendo sido encontradas ainda parteiras alemã, italiana e luxemburguesa. Havia as que atuavam na Santa Casa de Misericórdia e a que afirmava ser parteira da imperatriz. Algumas parteiras ofereciam cursos de partos, apresentando-se como professoras.

É notório que a partir da década de 1830 começou a aparecer e, até mesmo, aumentar o número de parteiras diplomadas. Nesse aspecto, afirmamos que, mais do que mudanças no perfil das parteiras atuantes nos centros urbanos como afirma Mott, ${ }^{14}$ houve o surgimento de outro perfil, ao menos, na cidade do Rio de Janeiro. A parteira formada, assim, não parece ter substituído a parteira com formação prática, mas criado uma nova possibilidade de atendimento ao parto, a partir de uma perspectiva acadêmica. Muitas dessas mulheres eram oriundas de outros países, sobretudo da França, nos quais a formação acadêmica já era prática comum. Ao chegarem à capital do Brasil, atenderam à demanda de parte da população por novos tipos de serviços. No entanto, o que pode ser percebido é que o aparecimento dessas parteiras na cidade não significou o desaparecimento de parteiras práticas, que continuaram atuando. Dessa forma, entendemos que o perfil da parteira não mudou, mas diferentes grupos passaram a coexistir.

Através da comparação entre Diário e Almanaque, podemos destacar algumas diferenças e semelhanças. As parteiras que anunciavam no Almanaque Laemmert deixavam evidente sua formação, em geral, em escolas francesas. Foram localizadas, nesse periódico, muitas parteiras estrangeiras, sobretudo provenientes da França. No Diário, foram encontradas mais parteiras brasileiras, com uma pequena parcela formada pela Faculdade do Rio de Janeiro. Também foram identificadas onze parteiras examinadas ainda pela Fisicaturamor (1808 a 1828), nas edições mais antigas, no período anterior a $1840^{15}$. Outra diferença é que no Diário do Rio de Janeiro não havia somente anúncios dos serviços de parteiras, mas também notícias, textos literários e críticas direcionadas a elas. A formatação do anúncio nesses dois veículos também é diferente: em geral, no Almanaque era mais direto e conciso, constando muitas vezes apenas o endereço da parteira e sua formação, enquanto no Diário havia,

\footnotetext{
${ }^{14}$ MOTT, op. cit., p. 119.

${ }^{15}$ Dados obtidos através do cruzamento com as pesquisas relativas à dissertação de PIMENTA, op. cit. e a monografia BARBOSA, Giselle Machado. A arte de partejar no Brasil: As parteiras legalizadas pela Fisicatura-mor (1808-1828). Monografia (Especialização em História do Brasil Colonial). Rio de Janeiro: Faculdade de São Bento do Rio de Janeiro, 2013.
} 
com maior frequência mais detalhes em relação à atuação da parteira, como indicações de que algumas ofereciam outros serviços, além da parturição.

\section{Aluguel de amas de leite e outros serviços}

A análise dos anúncios dos periódicos diários expôs um aspecto interessante do cotidiano dessas mulheres. Ao menos parte delas, lidava com aluguel de amas de leite, a criação de crianças de leite, ${ }^{16}$ aluguel de quartos para senhoras, aulas de partos ${ }^{17}$, sangrias ${ }^{18}$ e aplicação de ventosas,${ }^{19}$ cura de chagas no útero e de enfermidades em geral. A propaganda de outros serviços relacionados de alguma forma ao universo da maternidade e parturição provavelmente teria o intuito de destacá-las diante da concorrência. E, certamente, indica outros meios de obter rendimentos.

Madame Gault anunciou duas vezes no Diário do Rio de Janeiro em 1842. Na primeira publicação a parteira afirmava ser mestra e discípula da maternidade de Paris e oferecia o serviço de sangria. Na segunda, apresentava "seu préstimo nesta corte, onde já deu provas de aptidão" e informava que "as pessoas que se dignarem a honra-la com a sua confiança, encontrarão no modo de operar da anunciante, todas as garantias, e os mais extremosos cuidados, bem como sangra com perfeição" ${ }^{20}$ Em anúncios posteriores no Almanaque Laemmert, a parteira não menciona essa prática, apenas indicativa sua residência, situada na Rua da Ajuda, $\mathrm{n}^{0.64 .}$

Algumas parteiras se apresentaram como professoras e mestras, como as madames Kreft, Barbara Graf, Gault, Clementina Somjean, Landreau, Victorine

\footnotetext{
${ }^{16}$ No período moderno, em Portugal, era comum a entrega da criança à família de uma ama para que a mesma fosse criada durante a primeira infância até, aproximadamente, os sete anos, retornando à casa paterna em seguida. As mulheres da nobreza poderiam tanto contratar uma ama em domicílio como dar seu filho para que a ama criasse em sua própria casa, em geral, humilde. SÁ, Isabel dos Guimarães. As crianças e as idades da vida. In: MATTOSO, José (dir.). História da vida privada em Portugal. Idade Moderna. Lisboa: Círculo de Leitores, 2011, p. 72-93. Na pesquisa encontramos, a respeito das outras atividades desempenhadas por parteiras, o caso de Joaquina Batista que, em 1822, se dizia parteira, mas no anúncio oferece-se para criação de criança, sendo esse o primeiro anúncio encontrado no jornal Diário do Rio de Janeiro, 12 de abril de 1822, p. 34.

${ }^{17}$ Diário do Rio de Janeiro, 20 de março de 1832, p 64.

${ }^{18}$ Anúncio de 1842, de madame Gault, que se intitulava mestra parteira, discípula da Universidade de Paris. Diário do Rio de Janeiro, 28 de outubro de 1842, p. 4; e 29 de outubro de 1842, p. 4.

${ }^{19} \mathrm{Em} 1851$, a madame Kreft, dita viúva Wagner, anunciou no Almanaque que aplicava ventosas, assim como há um anúncio de D. Barbara Graf, em 1852 Almanaque Laemmert, 1851, p.302. Há dúvidas se Kreft e Graf são a mesma pessoa pelo fato de apresentarem a igual descrição de atividade: "Mestra parteira e aplica ventosas". Os endereços, ainda que diferentes nos anúncios, não foram feitos nos mesmos anos, sendo assim, não é possível, a partir desse dado afirmar serem pessoas distintas. Ver Almanaque Laemmert, 1852, p.364.

${ }^{20}$ Diário do Rio de Janeiro, 28 de outubro de 1842, p. 4 e 29 de outubro de 1842, p. 4.
} 
Borge e Louiza Vedova Paradiso, todas estrangeiras oriundas das França, com exceção desta última, proveniente da Itália. No entanto, apenas Estephania Maria Warnault, também chamada de madame Berthon (sobrenome adquirido pelo casamento), oferecia um curso de partos em sua residência para a aprovação em exame da Câmara Municipal, anunciado em 1832, no Diário do Rio de Janeiro. Sobre ela, sabe-se que foi aluna da Faculdade de Medicina de Paris, tendo realizado uma solicitação junto à Câmara Municipal do Rio de Janeiro para atuar no Brasil com sua "arte obstetrícia" em $1831 .^{21}$

Madame Clementina Somjean também se intitulava mestra parteira aprovada pela Faculdade de Medicina de Paris e do Rio de Janeiro. Anunciou de 1844 a 1870 no Almanaque Laemmert, com exceção de $1854^{22}$. Em 1846 começou a anunciar no Diário do Rio de Janeiro. Oferecia quartos às pensionistas onde, segundo o anúncio "encontrarão todos os cuidados e melhor tratamento possível”. Em 1857, Clementina anunciou aluguel de ama de leite, segundo ela, "com cria de 13 dias". ${ }^{23}$

Amas de leite também eram alugadas pelas parteiras Joana Baptista em $1830^{24}$ e Madame Meunier em 1840. Joana anunciou aluguel de mulher parda como ama de leite, enquanto Mme. Meunier, dizia que "aluga ama de leite e recebe qualquer em sua casa para ter cria para depois alugar ou vender". No ano seguinte a parteira divulgou que "o parto de escravas sai ao preço de 480 por dia e (\$?) pelo trabalho de parto.” Em 1846, afirmava na publicação do Diário do Rio de Janeiro ser a "parteira de S.M. Imperatriz" e no Almanaque Laemmert, a partir de 1847 até 1873, último anúncio encontrado, fez a mesma referência. ${ }^{25}$ Há indicações, portanto, sobre a associação entre auxiliar partos de escravos e o aluguel das amas de leite. Porém, não é possível afirmar que essa tenha sido uma atividade feita ao longo dos anos por Mme. Meunier.

A prática de alugar amas de leite foi bastante comum e algumas parteiras atuavam nesse ramo. Em seu trabalho, Mott ressalta que receber parturientes escravas e alugá-las como amas de leite foi uma entre as diversas atividades promovidas pelas parteiras no Brasil ao longo do século XIX.${ }^{26}$ Apesar de ser

\footnotetext{
${ }^{21}$ Arquivo Geral da Cidade do Rio de Janeiro - Fundo Câmara Municipal, série Ofícios e Profissões, Parteiras 1831.

${ }^{22}$ Diário do Rio de Janeiro, 17 de setembro de 1846, p. 4. Almanaque Laemmert, 1844, p.213; e 1870, p.480-1.

${ }^{23}$ Diário do Rio de Janeiro, 19 de agosto de 1857, p.3.

${ }^{24}$ Diário do Rio de Janeiro, 29 de novembro de 1830, p.3.

${ }^{25}$ A parteira aparece como o nome Meunier e Meonier. Diário do Rio de Janeiro, 9 de julho de 1840, p.3; 15 de janeiro de 1841, p.4, 23 de janeiro de 1841, p.4. 26 de janeiro de 1841, p. 4; 4 de setembro de 1846, p.4. Almanaque Laemmert, 1847, p. 290/291 e 1873, p. 533.

${ }^{26}$ MOTT, op. cit., p.117-118.
} 
uma prática comum no período, segundo a historiografia consultada, ${ }^{27}$ não foram encontradas nessa pesquisa muitas parteiras que oferecessem esse tipo de serviço. Nos jornais, havia uma seção exclusiva dedicada ao aluguel de amas de leite que, no entanto, não deixava evidente a identidade, profissão ou perfil do anunciante. As parteiras que anunciavam o aluguel de ama de leite costumavam se identificar no seu ofício, possivelmente, como uma forma de propaganda.

Importa destacar quem era essa ama de leite anunciada pelas parteiras. Segundo as fontes e a historiografia, eram mulheres negras e pardas, escravizadas, que haviam dado à luz recentemente. Esse tipo de serviço, à época denominado aleitamento "mercenário", era descrito como aquele em que a mulher amamentava uma criança mediante um pagamento previamente estipulado. Em se tratando de uma ama de leite escrava, o dinheiro da atividade iria para o seu proprietário. O termo empregado seria usado no discurso médico como forma de distinguir o aleitamento materno do artificial, sendo o termo "mercenário" ligado à ideia de trabalho por dinheiro, sem amor. ${ }^{28}$ Uma das estratégias utilizadas pelos senhores para alugar escravas como amas por preços mais altos era a de afastar o filho da mãe cativa, sendo esses levados para Roda dos Expostos da Santa Casa de Misericórdia. Dessa forma, o filho da contratante não teria que dividir o alimento. ${ }^{29}$

Esses serviços diversos que apareciam nos anúncios das parteiras, talvez como um chamativo a mais, deixaram de ser publicados nos periódicos pesquisados ao final da década de 1850. O aluguel de amas de leite foi anunciado por parteiras entre 1830 e 1857; a aplicação de ventosas, entre 1851 e 1853; a criação de crianças, apenas em 1822; sangrias, só em 1842; e as aulas de partos, entre 1832 e 1859. Dessa forma, mesmo que as parteiras (inclusive as que não anunciavam os seus serviços de parturição) continuassem a trabalhar com tais atividades, podemos apontar para uma tendência em especializar suas atividades em torno do parto. Ou, ainda, considerar que as parteiras formadas academicamente seriam mais reconhecidas pela sociedade e não teriam, portanto, a necessidade propagandear outros serviços em seus anúncios.

\footnotetext{
${ }^{27}$ CARULA, Karoline. Perigosas amas de leite: aleitamento materno, ciência e escravidão em a Mãi de Familia. História, Ciências, Saúde - Manguinhos, Rio de Janeiro, v.19, supl., dez. 2012, pp. 197-214; MOTT, op. cit; e SANGLARD, G; GIL, C. Assistência à infância filantropia e combate à mortalidade infantil no Rio de Janeiro (1889-1929). Revista da ABPN, v.6, 2014, p. 63-90.

${ }^{28}$ CARULA, op. cit., p. 199.

${ }^{29}$ Ibidem, p. 205. Sobre o assunto, ver Machado, Maria Helena. Entre dois Beneditos: histórias de amas de leite no ocaso da escravidão. In: XAVIER, Giovana et al (Orgs). Mulheres negras no Brasil escravista e do pós-emancipação. São Paulo: Selo Negro, 2012. p.199-213.
} 


\section{Um trabalho em conjunto}

O levantamento e análise dos anúncios das parteiras deixam evidente um aspecto pouco explorado pela historiografia, ainda que não seja ignorado. Trata-se das relações de amizade e trabalho entre as parteiras, sobretudo entre as formadas na academia. São associações de fato, compartilhando clientela ou residência.

O caso da parteira Durocher, sobre quem há mais informações do que a respeito das outras parteiras, é bastante interessante. A partir dos anúncios dos periódicos, foi possível identificar seus endereços e estabelecer as conexões que construiu na cidade. Durocher era francesa de nascimento e naturalizada brasileira, sendo formada no curso para parteiras da Faculdade de Medicina do Rio de Janeiro e construiu uma trajetória bastante reconhecida na sociedade da época. Sua rede de contatos incluía tanto parteiras como médicos. Constatamos que mudava com frequência o seu endereço, apresentando relações próximas de amizade com outras parteiras, o que a levou durante alguns períodos a dividir residência e, possivelmente, a clientela com elas. Esse aspecto é bastante revelador para compreender de que maneira a parteira interagia entre seus pares e como isso repercutiu no seu trabalho e das suas companheiras.

O primeiro anúncio da parteira Durocher foi encontrado no Diário do Rio de Janeiro no ano de 1837, no qual ela afirmou morar na Travessa do Núncio. Em seguida, o próximo endereço localizado da parteira, no ano de 1840, situava-se na Rua do Hospício, no. 8. Não foi possível saber com precisão por quanto tempo residiu ali, pois há um espaço de quatro anos em que não publicou reclames. No entanto, outro anúncio em 1844, mostrava já uma nova residência. Assim, de 1844 a 1846 a parteira Durocher permaneceu instalada à Rua das Violas, no. 160. Em seguida, no ano de 1847 , partiu para a Rua do Sabão, no. 170, $1^{\circ}$ andar, onde morou por 16 anos, segundo ela mesma afirmou em anúncio. ${ }^{30}$

Em 1861, a parteira Durocher anunciou a mudança para a casa da parteira Felicíssima Roza Pereira Ferreira, sua "comadre, amiga e colega", ${ }^{31}$ como ela

\footnotetext{
${ }^{30}$ Diário do Rio de Janeiro, 13 de julho de 1840, p. 4; A Rua das Violas teve seu nome alterado para Rua Teófilo Otoni, porém a mudança não ocorreu durante o período em que Durocher residiu. Diário do Rio de Janeiro, 8 de fevereiro de 1861, p. 3, 10 de fevereiro de 1861, p.3, 14 de fevereiro de 1861, p. 4, 16 de fevereiro de 1861, p. 3, 17 de fevereiro de 1861, p.3, 18 de fevereiro de 1861, p. 3, 20 de fevereiro de 1861, p. 4, 22 de fevereiro de 1861, p. 3.

${ }^{31}$ Diário do Rio de Janeiro, 8 de fevereiro de 1861, p. 3, 10 de fevereiro de 1861, p.3, 14 de fevereiro de 1861, p. 4, 16 de fevereiro de 1861, p. 3, 17 de fevereiro de 1861, p.3, 18 de fevereiro de 1861, p. 3, 20 de fevereiro de 1861, p. 4; 22 de fevereiro de 1861, p. 3. Em https://bndigital.bn.br/hemeroteca-digital/, consultado em junho de 2015
} 
própria afirmou, indicando não apenas a parceria na profissão como também a amizade entre elas, o que aponta para laços de solidariedade e ajuda mútua entre as parteiras. Essas relações são apresentadas por Mott, que afirma que morar na mesma casa "revela identidade, solidariedade e confluência de interesses entre profissionais, tais como divisão de despesas e compartilhamento de clientela". ${ }^{32}$

Nesse local, permaneceu, ao que as fontes indicam, até 1864, quando voltou para a Rua do Sabão, dessa vez no número 113. De acordo com anúncios do Almanaque Laemmert, a parteira Felicíssima residiu no endereço Rua da Imperatriz, no. 41, entre 1861 e 1871, ou seja, momento em que dividiu casa com Durocher. Após esse período, Felicíssima se mudou para Rua Conde de Bonfim, onde pode ter permanecido até seu falecimento, em 1872.33

Interessante destacar que, em 1870, a parteira Isabel de Moraes Silva anunciou no Diário do Rio de Janeiro seus serviços para esse mesmo endereço, afirmando que "presta-se a qualquer hora para os misteres de sua profissão: chamados por escrito, na casa de sua residência, à Rua da Imperatriz, no. 41, sobrado, onde residiu a parteira Felicíssima Ferreira, e a quem substituiu a anunciante". Das atividades desenvolvidas, além do parto, Isabel oferecia quartos para pensionistas. ${ }^{34}$

Em 1863, na seção do jornal intitulada "publicações a pedido", a parteira Durocher publicou uma nota com algumas informações a respeito da maternidade da Casa de Saúde de Nossa Senhora da Ajuda. No texto, a parteira escrevia para aqueles que "diariamente lhe pedem informações a respeito da maternidade ou enfermaria de partos" (...), que em sua ausência, quem iria assistir aos partos seria a parteira Tygna, e que, em casos mais perigosos o dr. Feijó seria chamado. Ao final do comunicado, Durocher afirmava ser possível se dirigir à sua residência ou a da parteira Tygna para tratar, caso não quisesse fazê-lo no estabelecimento. Tygna continuou atuando em clínica no ano seguinte, em 1864, dividindo-se assim entre o atendimento domiciliar e o trabalho na casa de saúde, bem como faziam as outras parteiras.

A relação próxima entre as duas parteiras pode ser observada a partir dos anúncios individuais de cada uma delas. Tygna publicou que caso não

\footnotetext{
${ }^{32}$ MOTT, op. cit. p. 122.

${ }^{33}$ Informativo sobre enterro da parteira Felicíssima, realizado no Cemitério São Francisco Xavier, saindo o enterro da Rua Imperatriz, n. 41, no dia 19 de setembro, às 10 horas da manhã. Cita alguns nomes de amigos e familiares: Firmino Passos Pereira Ferreira, Juvêncio Pereira Ferreira, D. Luiza Pereira Ferreira e seus filhos, D. Felisberta Faustina Torres, João José Torres, José Martins Torres e a Parteira Durocher. Diário do Rio de Janeiro, 15 de setembro de 1872, p. 4.
}

${ }^{34}$ Diário do Rio de Janeiro, 24 de abril de 1870, p. 4. 
fosse encontrada em sua residência, a parturiente poderia procurar as parteiras Durocher e Ferreira, residentes no mesmo endereço. Como apontamos, algumas parteiras dividiam moradia, como é o caso de Durocher, que residiu na mesma casa que Felicíssima Rosa Pereira Ferreira, e mais tarde, mudou-se para a casa de Tygna.

Há a possibilidade de que alguns desses endereços fossem apenas locais de atuação e não o local de sua residência, uma vez que no mesmo ano apareceram endereços diferentes da parteira. Em anúncio de 1873 no Diário do Rio de Janeiro, Durocher afirmou atuar no consultório do dr. Paula Menezes, situado no Largo do Capim, no. 50, onde prestava consultas das 10 horas ao meio dia. Outro documento, uma receita expedida pelo médico citado, que continha a referência a Durocher como sua colaboradora, confirmou a atuação em conjunto de Durocher e Paula Menezes. ${ }^{35}$

Acompanhando outras mudanças de endereço, também temos indícios sobre as relações estabelecidas entre outras parteiras. Em 1864, Borgé se mudou da Rua da Assembleia para a Rua da Alfândega, no.92, segundo o anúncio "antiga casa de Mme. Stefhania Berthon", ${ }^{36}$ o que não significa que fossem colegas, porém, pode ter havido algum contato entre elas. Essa prática de residir na mesma casa na qual havia morado outra parteira anteriormente foi encontrada algumas vezes. Antes disso, Borgé morou na Rua da Assembleia, no. 102 e na Rua de Santo Antônio, no. 34, próximo ao Largo da Carioca.

Outros exemplos indicam que as parteiras formadas se mudavam com certa frequência e, muitas vezes, se estabeleciam em locais que já haviam sido habitados por outra parteira. Assim, a casa situada à Rua da Ajuda, no. 55, pertenceu à madame Pascal, entre 1840 e 1848, e a partir de 1849 passou a residir ali a parteira madame Pourtois até 1858. Na Rua do Rosário, no. 98, Clementina Somjean oferecia quartos para pensionistas em 1844 e no ano seguinte anunciava outro endereço, ainda com o mesmo serviço. Em 1853, foi a parteira Felícia Hautefeuille, formada na escola de medicina de Paris, que anunciava serviço de consultas e recebia pensionistas no mesmo endereço em que antes residiu Somjean. ${ }^{37}$ Podemos pensar que essa mudança para o

\footnotetext{
${ }^{35}$ Diário do Rio de Janeiro, 28 de outubro de 1873, p. 4. Receituário expedido pelo consultório do dr. Araújo Filho e da Parteira Durocher. Arquivo Geral da Cidade do Rio de Janeiro - Fundo Câmara Municipal, Parteiras (1830-1878).

${ }^{36}$ Madame Borgé morou na Rua da Uruguaiana, n. 2, nos mesmos anos em que Madame Gaulier anunciou neste endereço. Almanaque Laemmert, 1883, p. 750/751, 1884, p. 818, 1885, p. 795, 1886, p. 902/903, 1887, p. 907.

${ }^{37}$ Diário do Rio de Janeiro, 6 de junho de 1840, p. 4; 13 de julho de 1840, p. 4; 23 de setembro de 1840, p. 4; 30 de abril de 1841, p. 4; 25 de maio de 1841, p. 4; 26 de julho de 1841, p. 4; 5 de outubro de 1841, p. 4; 19 de outubro de 1841, p.4; 26 de novembro de 1841, p. 4; 26 de março de 1842, p.4; 15 de julho de 1842, p.
} 
endereço de outra parteira poderia ser útil, uma vez que isso possibilitaria o aproveitamento de um ponto já estabelecido por outra e permitiria a elas receberem as freguesas das proximidades. Além disso, se mudar para a residência de uma parteira conhecida como Durocher ou Felicíssima, como no caso de Isabel, pode ter significado uma forma de propaganda e promoção do seu trabalho. Não por acaso, as parteiras mencionaram tal fato nos seus anúncios. Ao fazerem isso, poderiam aproveitar tanto a clientela já conquistada do local, quanto o contato de uma parteira famosa como se ela tivesse recebido uma recomendação, fazendo parte, assim, de uma rede de contatos de parteiras.

Outra questão importante acerca dos endereços anunciados diz respeito à localização. A maioria das parteiras mais antigas, que havia sido examinada pela Fisicatura-mor tinha apenas licença da Câmara Municipal, morava em regiões mais periféricas do centro, sendo em muitos casos, endereços como travessas, becos ou ruas pequenas. As parteiras com formação acadêmica, por sua vez, apareciam em grande número habitando ruas centrais, mais próximas à Rua do Ouvidor e ao Largo da Carioca. Além disso, moravam próximas umas das outras, como as parteiras Pourtois e Maria del Carme Pavia Brioso, que moraram na Rua da Ajuda, no. 55 e no. 89 no mesmo período. ${ }^{38}$

Voltando à trajetória de madame Borgé, verificamos que ela anunciou em 1874 no Almanaque Laemmert uma referência à Maria Müller, afirmando que "no mesmo endereço pode-se encontrar a colega de profissão". Em 1875, um anúncio da madame Maria Muller, apresenta o endereço em seguida da frase "casa de Mme. Borgé". Essas informações indicam que elas dividiram residência até pelo menos o ano de 1876, quando Borgé se mudou. A respeito da maternidade que levava o seu nome, Borgé afirmava na descrição que "continua com sua casa à ladeira de Santo Antonio no.2, esquina da Rua da Guarda Velha, onde a qualquer hora é sempre encontrada para os misteres de sua profissão, ou sua colega Mme Maria Müller", e que "Continua a receber pensionistas pelos preços mais moderados possíveis." ${ }^{39}$ Até o ano 1879, Victorina Borgé publicou propagandas de sua maternidade, sendo alguns dos anúncios feitos por sua colega, Müller. A respeito da associação com Maria Müller, a

4; 7 de março de 1845, p. 4; 27 de março de 1845, p. 4; 21 de abril de 1845, p.8;17 de maio de 1845, p.4; 25 de agosto de 1845 , p.4; 15 de setembro de 1845, p. $4 ; 4$ de setembro de 1846, p. 4. E Almanaque Laemmert, 1847 , p. 290/291 e 1848, p. 333. Almanaque Laemmert 1849, p. 268; 1850, p. 298, 1851, p. 302, 1852, p. 364/ suplemento 187, 1854, p. 374/373, 1855, p. 412/413, 1856, p. 440, 1857, p. 473. Almanaque Laemmert, 1844, p. 213, 1845, p. 226, 1847 e p. 290/291. Almanaque Laemmert, 1853, p. 374, 1854, p. 374/375 e 1856, p. 440.

${ }^{38}$ Madame Brioso residiu na Rua da Ajuda, n. 89, Almanaque Laemmert, 1857, p. 473. E Madame Pourtois estabeleceu-se na Rua da Ajuda, n. 55, Almanaque Laemmert, 1857, p. 473.

${ }^{39}$ Almanaque Laemmert, 1874, p. 586; 1875, p. 644; 1877, p. 708/709; 1874, p.586; 1875, p. 644; 1876, p. 693. 
mesma não foi localizada após 1874, sendo o próximo anúncio de Borgé em 1875, sem, no entanto, mencionar a parteira, mas ainda no mesmo endereço.

Em 1879, Borgé anunciou outro endereço, dessa vez com associação de Maria Hildenwirth. A mesma se manteve nos anos 1880, 1881 e 1882, data do último anúncio. A parteira Hildenwirth em dois anúncios foi mencionada como diretora da maternidade, sendo o nome principal mantido como Maternidade de Mme. Borgé. Não foi possível saber se a maternidade ou a associação permaneceu após esse período, entretanto, sabe-se que as duas parteiras apresentaram mesmo endereço de residência em $1883,{ }^{40}$ indicando que ainda dividiam casa e clientela. Interessante destacar que Borgé recebeu pensionistas em residência durante anos, sendo esse um dos principais serviços prestado por ela.

A parteira Victorine Borgé residiu na mesma casa de Pauline Gaulier entre os anos 1883 e 1887. Nota-se que Gaulier, a partir de 1888, mudou sua apresentação de madame para veuve, viúva em francês, o que seria indício de ter sido casada antes. Nesse mesmo ano, Gaulier anunciou um novo endereço e oferecia os seus serviços até pelo menos 1889. Sobre Borgé, não foi possível saber se houve mudança para outro endereço, pois o seu último anúncio encontrado se deu em 1887, ainda na Uruguaiana, no. $2 .{ }^{41}$ Apesar do aparente compartilhamento de endereços, não foram encontradas referências de uma a outra nos anúncios, como aconteceu com outras parteiras de dividiram casa e clientes.

\section{Casas de parteiras, maternidades e casas de saúde}

Através dos anúncios, é possível também identificar os locais onde essas parteiras costumavam atuar. Se o parto domiciliar continuava a predominar durante todo o século XIX no Rio de Janeiro, outros locais passaram a ser cada vez mais utilizados para se dar à luz. E foram as parteiras formadas na academia que ofereciam esses novos espaços. Continuavam a anunciar os seus endereços para serem chamadas à casa da parturiente, mas muitas também diziam ter quartos em sua residência para clientes, como a madame Berthon, francesa, que era parteira da Santa Casa de Misericórdia e anunciou em três edições do Diário do Rio de Janeiro em 1833. Além disso, dizia encarregar-se

\footnotetext{
${ }^{40}$ Almanaque Laemmert, 1879 , p. 666/667,1880, p.700/701; 1881, p. 717/718; 1881, p. 717/718; 1883, p. $750 / 751$. ${ }^{41}$ Almanaque Laemmert, 1888, p. 920 e 1889, p. 931; 1889, p. 931; 1887, p. 907.
} 
de escravas por preços cômodos, como consta também em anúncio de 1836 em $O$ Paquete do Rio de Janeiro, no qual publicou cinco vezes. ${ }^{42}$

Victorine Borgé realizou seu primeiro anúncio em 1858 no Almanaque, publicando apenas seu endereço anualmente até que, em 1874, anunciou maternidade. Nesse ano, a parteira anunciou ser formada pela Faculdade de Medicina de Paris recebendo pensionistas em sua casa, juntamente com a parteira Maria Müller, da Escola de Medicina do Rio de Janeiro. Pensionistas seriam aquelas mulheres que, em vez de terem seus partos em casa, como o usual, optavam por se alojar na casa de uma parteira para este fim, ou ainda, poderia haver alguma situação de discrição em relação à gravidez. Já no Diário do Rio de Janeiro, a parteira Borgé teve seu primeiro anúncio em 1860, publicando neste ano diversas vezes com o mesmo conteúdo, no qual afirma ser examinada pelas Faculdades de Paris e Rio de Janeiro e ainda receber pensionistas estrangeiras e falar alemão. Nos anos subsequentes, a parteira continuou a publicar nesse mesmo periódico até 1869 , quando anunciou cura para pernas inchadas no endereço de sua residência, o mesmo da maternidade que possuía em seu nome. ${ }^{43}$

A parteira Louiza Vedova Paradiso também divulgava os seus serviços em 1848, afirmando receber pensionistas "de qualquer grau e qualidade por ter cômodos apropriados para esse fim", ${ }^{44}$ assim como Madame Victorina Borgé, a que mais propagandeou receber parturientes. Borgé anunciou no Diário do Rio de Janeiro uma vez em 1858, 36 em 1860 e 44 em 1864. No Almanaque, publicou 28 anúncios acerca de pensionistas e 4 sobre sua maternidade.

Esse tipo de anúncio era mais comumente encontrado no Diário do Rio de Janeiro do que no Almanaque Laemmert. Devemos levar em conta a periodização de cada um, sendo um diário e o outro, anuário. Segundo, observamos que, geralmente, não se anunciava mais do que nome e endereço no Almanaque. Ao contrário, no Diário do Rio de Janeiro, os anúncios eram, com frequência, mais detalhistas, contendo informações a respeito de atividades, formação e outros dados sobre a anunciante. De qualquer modo, por se tratar de um jornal popular, é possível que a atividade fosse direcionada a um público mais popular e a donos de escravos, já que a maioria das mulheres dava à luz em

\footnotetext{
${ }^{42}$ Diário do Rio de Janeiro, $1^{\circ}$ de maio de 1833, sem página, 21 de maio de 1833, sem página, 16 de agosto de 1833, sem página; O Paquete do Rio, 30 de maio de 1836, p. 775, 4 de julho de 1836, p. 4, 16 de julho de 1836, p.4, 18 de julho de 1836, p. 3, 27 de setembro de 1836, p.3.

${ }^{43}$ Almanaque Laemmert, 1858, p.482; 1874, p. 586; Diário do Rio de Janeiro, 2 de outubro de 1860, p.4; 6 de outubro de 1864, p.3; 12 de maio de1869, p.4.

${ }^{44}$ Diário do Rio de Janeiro, 20 de setembro de 1858, p.4.
} 
sua própria casa. Além disso, instalar-se na casa de uma parteira pode estar ligado à procura de discrição em relação à gravidez, seja para a realização de um parto ou a um possível aborto.

No entanto, a partir de 1873, começaram a ser publicados no Almanaque anúncios de maternidades criadas e dirigidas por parteiras, como a da madame Daure. Qual seria a diferença entre a oferta de quartos para pensionistas grávidas e a casa de maternidade? Ao que parece, pela verificação das fontes, seria o fato de a casa de maternidade estar enquadrada na categoria de casas de negócio, enquanto o aluguel de quartos poderia ser apenas um diferencial de uma parteira na conquista de freguesia. No caso das maternidades, era preciso uma licença adquirida junto à Câmara Municipal. Ou seja, apesar de as parteiras anunciarem que recebiam pensionistas, não era permitido que fizessem de sua residência uma casa de partos ou maternidade sem autorização. Um edital de 13 de dezembro de 1844 da Câmara Municipal determinava que "Todos os que tiverem casa de negócio de qualquer natureza e qualidade que seja, bem como boticas, oficinas, escritórios, tendas ou barracas serão obrigadas a tirar todos os anos uma licença e pagar todos os impostos que lhe competem", estando as casas de maternidade entendidas como casa de negócio. ${ }^{45}$

Em dezembro de 1878, Durocher foi acusada de ter em sua residência uma casa de maternidade e, por isso, foi intimada a pagar uma multa. A parteira recorreu em carta ao subdelegado do $2^{\circ}$ distrito da Freguesia do Sacramento alegando ter ocorrido um engano, pois não tinha em sua casa uma maternidade. $O$ inspetor, então, em visita à casa da parteira constatou que não havia maternidade, mas apenas o nome da porta indicando a sua profissão. Uma carta também foi enviada ao presidente da Câmara pedindo que se retirasse a acusação e a multa com a alegação de que "desde que exerce sua profissão nunca se entregou às especulações de casa de maternidade" e que "o que sempre tem tido é um consultório conjuntamente com um médico" ${ }^{46}$

Dois casos encontrados mostraram a possibilidade de parteiras possuírem um escritório de partos. Alexandrina Maria Leopold foi acusada de ter uma casa de partos e de nunca ter pagado imposto à Câmara em quinze anos de exercício do oficio. Desse modo, o fiscal a intimou a pagar multa por ter um escritório de partos. Alexandrina recorreu, afirmando não possuir escritório,

\footnotetext{
${ }^{45}$ Almanaque Laemmert, 1873, p. 533; Arquivo Geral da Cidade do Rio de Janeiro - Fundo Câmara Municipal. Editais da Câmara Municipal de 1844.

${ }^{46}$ Arquivo Geral da Cidade do Rio de Janeiro - Fundo Câmara Municipal, Série Ofícios e Profissões, Parteiras (1830-1878), 6 de dezembro de 1878 e 19 de abril de 1878. pp. 17-18.
} 
apenas exercer a arte de parteira. Outra situação ocorreu em 1879, quando a veuve Cocural também entrou com um pedido para a retirada de uma multa que lhe foi imposta por possuir em sua residência uma casa de maternidade, o que, segundo ela, não seria verdade. A madame afirmou não possuir casa de maternidade, mas um escritório de partos e, dessa forma, não havia motivos para a penalidade aplicada. Uma observação inserida no requerimento de Cocural indica que o pedido foi aceito ao afirmar que "a suplicante não tem (...) maternidade". ${ }^{47}$

Nos periódicos não foram encontradas referências a escritório de partos e, portanto, não foi possível identificar quais parteiras possuíam ou que tipo de prática era realizada nele. A questão que se coloca é: um escritório de partos seria o mesmo que um consultório para o atendimento de clientes? Identificamos apenas que ter escritório sem pagamento de imposto decorreria em multa e que ter um escritório não era o mesmo que possuir uma casa de maternidade ${ }^{48}$.

Dar à luz fora de sua residência por muito tempo foi considerada uma situação anormal, considerada arriscada, só ocorrendo em casos extremos, de grande dificuldade. As mulheres mais pobres, que podiam ser indigentes, prostitutas ou mães solteiras, em geral, eram as que buscavam atendimento nas Santas Casas, instituições mantidas por caridade religiosa ou benemerência. A chegada das parteiras estrangeiras ao Brasil trouxe uma novidade ao cuidado das parturientes: antes atendidas em domicílio, passaram a ter como opção a casa da parteira. Aos poucos, afirma Mott, esse atendimento é ampliado e passado a ser reconhecido como casa de maternidade. Nesses locais, atendiam-se mulheres negras escravizadas, livres, mães solteiras e viúvas. As casas eram alvo do julgamento moral da sociedade que a via como locais em que se recebiam mulheres para práticas como aborto e, portanto, eram desqualificados. ${ }^{49} \mathrm{Em}$ geral, as casas de maternidades tinham lugar na própria casa da parteira, ou seja, o local de trabalho não era separado da residência.

De modo geral, os anúncios sobre maternidades vinham após os referentes às parteiras, com uma formatação diferente, maior e com maiores detalhes. Conforme a análise das informações dadas, podem-se levantar algumas

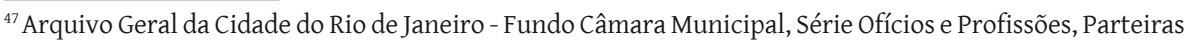
(1830-1878), s/data, p.15-16; Parteiras: Requerimento de Mme. Cavenal, ou Cocural, declarando não ter casa de maternidade (1879).

${ }^{48}$ Não encontramos referência ao assunto na bibliografia consultada.

${ }^{49}$ MOTT, Maria Lúcia. Assistência ao parto: Do domicílio ao hospital (1830-1960). Proj. História, 25, 2002, p. 197-219. p. 199.
} 
questões como a correspondência entre os endereços das maternidades e os das parteiras proprietárias entre aqueles em que foi possível proceder a comparação. Isso porque aquelas que anunciavam maternidade continuavam anunciando, por vezes, seu serviço como parteira. Foram identificadas sete maternidades. 0 quadro a seguir apresenta a relação das parteiras e as casas de maternidade que elas abriram.

Quadro - Casas de maternidade de parteiras

\begin{tabular}{|c|c|c|c|}
\hline MATERNIDADE & SERVIÇOS & PERÍODO & ENDEREÇO \\
\hline $\begin{array}{l}\text { Enfermaria de partos do } \\
\text { Dr. Pereira de Souza e da } \\
\text { parteira Tereza Jesuína } \\
\text { Tygna }\end{array}$ & Não informado & 1861 & $\begin{array}{l}\text { Rua do Sabão, 170, } \\
\text { loja }\end{array}$ \\
\hline $\begin{array}{l}\text { Maternidade } \\
\text { MmeDaure } \\
\text { Maternidade São Vicente } \\
\text { de Paula (1875) }\end{array}$ & $\begin{array}{l}\text { Recebe pensionistas; } \\
\text { Consultas } \\
\text { Coadjuvado com médicos } \\
\text { especialistas em parto. } \\
\text { Parteiras Adjuntas }\end{array}$ & $\begin{array}{l}1873 a \\
1881\end{array}$ & $\begin{array}{l}\text { Rua do Espírito Santo, } \\
20 \\
\text { Travessa da Barreira, } \\
43 \text { (1875) } \\
\text { Rua do Espírito Santo, } \\
27 \text { (1877) }\end{array}$ \\
\hline $\begin{array}{l}\text { Maternidade MmeBorgé } \\
\text { (com Mme Maria Müller). } \\
\text { Maternidade } \\
\text { MmeBorgé (dirigida por } \\
\text { MmeHildenwirth) (1879) }\end{array}$ & Recebe freguesas e pensionistas & $\begin{array}{l}1874 a \\
1882\end{array}$ & $\begin{array}{l}\text { Ladeira de Santo } \\
\text { Antonio, } 2 \\
\text { Rua de Santo Antônio, } \\
34\end{array}$ \\
\hline $\begin{array}{l}\text { Maternidade Mme } \\
\text { Marguerite. }\end{array}$ & $\begin{array}{l}\text { Recebe pensionistas; } \\
\text { Tratamento do útero; } \\
\text { Atende chamados dentro e fora } \\
\text { da cidade; médico interno dr. José } \\
\text { Ferreira Barreto.Médico interno: } \\
\text { dr. Gabizo (1877); Médico interno: } \\
\text { dr. Macedo Soares (1878) }\end{array}$ & $\begin{array}{l}1876 a \\
1879\end{array}$ & $\begin{array}{l}\text { Rua da Guarda Velha, } \\
1 \\
\text { Rua de Gonçalves } \\
\text { Dias, } 37 \text { (1877) }\end{array}$ \\
\hline $\begin{array}{l}\text { Maternidade Saint Marie } \\
\text { MmeDunugon. }\end{array}$ & $\begin{array}{l}\text { Recebe pensionistas; } \\
\text { Consultas de meio dia às } 2 \mathrm{~h}\end{array}$ & 1877 & Rua da Uruguaiana, 2 \\
\hline $\begin{array}{l}\text { Maternidade de Sant'Anna } \\
\text { MmeBardeaud }\end{array}$ & $\begin{array}{l}\text { Recebe pensionistas; } \\
\text { Atendimento dentro e fora da } \\
\text { cidade }\end{array}$ & 1878 & $\begin{array}{l}\text { Rua do Espírito Santo, } \\
4\end{array}$ \\
\hline $\begin{array}{l}\text { Maternidade de Mme } \\
\text { Jeanne Grangent }\end{array}$ & $\begin{array}{l}\text { Recebe pensionistas; } \\
\text { Acompanhada de médicos } \\
\text { parteiros; Atende dentro e fora } \\
\text { da corte }\end{array}$ & 1878 & $\begin{array}{l}\text { Rua da Assembleia, } \\
33,1^{\circ}, 2^{\circ} \text { e } 3^{\circ} \text { andares }\end{array}$ \\
\hline
\end{tabular}

Fonte: Almanaque Laemmert, 1861-1882. 
Em anúncio de $1873,{ }^{50}$ madame Daure publicou que abriu uma maternidade para receber pensionistas em sua residência. De acordo com o anúncio, os preços eram moderados, oferecendo "todas as comodidades e tratamento esmerado." Em 1875 e 1876 a mesma parteira anunciou sua maternidade, dessa vez com um nome: Maternidade São Vicente de Paula.

Madame Marguerite apresentou, em 1876, no Almanaque Laemmert, maternidade que carregava o seu nome. Além do atendimento de parturientes, Marguerite também oferecia tratamento do útero no período da tarde. No estabelecimento, havia um médico interno, o dr. José Ferreira Barreto. Não foram informados detalhes a respeito do médico quanto à sua formação ou mesmo se possuía uma função mais específica na maternidade como, por exemplo, o cuidado de moléstias ou parturição. Em 1877, além de mudar de endereço, a maternidade recebe um novo médico, o dr. Gabiso, possivelmente em substituição ao médico anterior, pois aquele não foi mencionado em outras publicações da parteira. Em 1878, o dr. Macedo Soares foi chamado, continuando no ano seguinte..$^{51}$ Os anúncios de Mme. Marguerite como parteira foram publicados desde 1869 até 1871 , sendo os subsequentes relacionados à sua maternidade, até pelo menos 1879. A presença de um médico atuando junto da parteira pode indicar que a mesma seguia aquilo que era determinado pelos médicos e faculdades de medicina ao disporem sobre a divisão do trabalho. A parteira manteve médicos que possivelmente atuariam em partos dificultosos que necessitassem a intervenção de instrumentos específicos, os quais as parteiras não estariam habilitadas a usar, ainda que fossem formadas.

A parteira Dunugon trouxe a público, em 1877, a maternidade Saint Marie, da qual era a proprietária. Disse ser premiada com medalha de ouro pela Faculdade de Medicina de Paris. Em outros anúncios posteriores a parteira não mencionou esse estabelecimento, apenas os seus serviços. Interessante destacar que a parteira apresentava dois endereços, um que corresponde à maternidade, onde ficava de meio dia às 2 horas da tarde, e outro possivelmente de sua residência, atendendo das 2 às 5 horas da tarde.

A maternidade de Sant'Anna era dirigida por madame Bardeaud, recebia pensionistas de qualquer cor ou condição sem distinção e contava com "excelentes cômodos bem arejados" de acordo com anúncio de 1878. ${ }^{52}$ Não há outras propagandas de seu estabelecimento, sendo as dos anos anteriores

\footnotetext{
${ }^{50}$ Almanaque Laemmert, 1873 , p. 533.

${ }^{51}$ Almanaque Laemmert, 1876, p.693; 1877, p.708/709; 1878, p.645/646/647.

${ }^{52}$ Almanaque Laemmert, 1878, p.645-7.
} 
apenas relativas ao serviço de parteira com atendimento domiciliar. A partir de notícia do jornal Diário do Rio de Janeiro, sabe-se que a parteira realizou exame de suficiência para o ofício em 1874, na Faculdade de Medicina do Rio de Janeiro, tendo sido formada pela Faculdade de Medicina de Montpellier.

Ocupando o $1^{\circ}, 2^{\circ}$ e $3^{\circ}$ andar de um prédio na Rua da Assembleia, a maternidade de Mme Jeanne Grangent parecia ser bastante espaçosa. De acordo com o anúncio, recebia pensionistas tanto escravas como livres por preços que dizia serem módicos, podendo ser acomodadas em quartos separados, também havia cômodos para famílias que viessem do interior. Afirmava ser acompanhada dos melhores médicos parteiros, que poderiam ser chamados nos casos em que houvesse necessidade.

Essas são algumas parteiras que conseguiram criar uma casa de partos ou maternidade, que podia se localizar em sua residência ou em prédio à parte. Em geral, as proprietárias de maternidade diziam receber pensionistas nos anúncios. Porém, não foi possível determinar se as outras parteiras que também anunciavam receber pensionistas possuíam uma maternidade em suas casas. Desse modo, como foi dito, levou-se em consideração que o serviço de pensionistas, nas quais a parteira atuava em sua própria residência, não pode ser confundido com o de casa de parto ou maternidade, sendo esses estabelecimentos geralmente especificados nos anúncios. Além disso, para possuir escritórios de parto e casas de parto ou maternidade era preciso uma autorização sem a qual corria-se o risco de receber multa, sendo talvez esse o motivo pelo qual elas não anunciariam uma possível maternidade. Observouse ainda que a maior parte das publicações sobre serviços de maternidade foram encontradas no Almanaque Laemmert. Nos demais periódicos, as parteiras apenas ofereciam quartos ou pensão. Infere-se que o tipo de periódico pode ter relação com a clientela que procurava a maternidade, já que foram localizados anúncios no Almanaque Laemmert, um periódico dedicado a um público mais abastado. Isso porque, devido à carência de maternidade ou ainda pelo costume de se ter filhos em domicílio, as maternidades das casas de saúde e as casas de maternidade promovidas pelas parteiras poderiam representar uma alternativa à hospitalização nas Santas Casas, lugares frequentados por mulheres mais pobres, indigentes, prostitutas e mães solteiras. ${ }^{53}$

Assim como muitas parteiras mudavam com frequência de endereço, as casas de maternidade também tiveram seus endereços modificados, em conformidade com a residência da parteira proprietária ou diretora. Entretanto,

${ }^{53}$ MOTT, M. L. Assistência ao parto: Do domicílio ao hospital (1830-1960). Proj. História, 25, 2002, p. $197-219$. p. 198. 
essas mudanças não apareceram com a mesma frequência no periódico. Os anúncios de maternidade não eram tão numerosos quanto o das parteiras, assim, são poucas as informações a respeito dessas casas. De qualquer forma, os anúncios encontrados demonstram que cada maternidade se deslocou pelo menos uma vez e, ao que se sabe, de acordo com o próprio endereço da parteira proprietária.

Outro espaço de atuação para as parteiras era a casa de saúde, cujos proprietários costumavam ser médicos. Algumas casas de saúde recebiam parturientes. No Diário do Rio de Janeiro foram encontradas quatro casas de saúde que contavam com parteiras como funcionárias: a Casa de Saúde Nossa Senhora da Ajuda, Casa de Saúde Nossa Senhora da Glória, Casa de Saúde São Sebastião e a Casa de Saúde do Morro de São Lourenço. Todas possuíam salas de parto, nas quais as parteiras atuavam apenas em partos sem complicações. Essas salas eram dirigidas por médicos obstetras. Outras casas de saúde encontradas no Almanaque Laemmert possuíam uma maternidade nas suas dependências, no entanto sem parteiras atuantes, apenas médicos parteiros. Depois de 1863, só duas casas de saúde apresentaram parteiras em sua propaganda uma única vez: a casa de Saúde de São Sebastião, com madame Gault, em 1874, e a Casa de Saúde no Morro do São Lourenço, com madame Braune, em 1880. Portanto, a maioria das Casas de Saúde não contava com parteiras em seu quadro de funcionários ou, simplesmente, não anunciava a sua presença.

De acordo com Magalhães, citado por Mott no artigo Assistência ao parto: do Domicílio ao hospital, as casas de saúde no Rio de Janeiro se propagaram, sobretudo devido à necessidade dos senhores terem um local para cuidar dos escravos. Nesses estabelecimentos, os quartos eram separados para diferenciar a clientela livre da escravizada. ${ }^{54}$ De fato, como pode ser observado nos anúncios, as casas de saúde, em geral, possuíam quartos para escravos com preço diferenciado, mais barato que para a clientela livre.

A Casa de Saúde de Nossa Senhora da Ajuda, situada à Rua da Ajuda, n. 68, cujo diretor e proprietário era dr. Eiras, teria um anexo ao prédio principal, com jardim, quartos de banho e cômodos para uma maternidade. Esse último ficaria a cargo da parteira Durocher, desde 1862, e sob a direção médico Feijó. O médico seria chamado sempre nos casos mais graves, sendo a parteira que atuaria nos partos tranquilos. Ou seja, apesar de a parteira, ainda que com instrução formal e de renome como Durocher, ocupar uma função importante

\footnotetext{
${ }^{54}$ MAGALHES, F. A obstetrícia no Brasil. Rio de Janeiro, Leite Ribeiro, 1922a, p. 218. Apud MOTT, M.L. Assistência ao parto: do domicílio ao hospital (1830-1960). Proj. História. São Paulo, (25), dez. 2002. pp. 197-219.
} 
na maternidade da casa de saúde, sempre haveria o médico a substituí-la em momentos em que não se atribuía competência a ela. Delimitava-se, assim, os espaços ocupados por cada um, a despeito dos conhecimentos teóricos e vasta experiência da parteira Durocher.

No ano seguinte, a própria Durocher, no Diário do Rio de Janeiro, escreveu "para tirar as dúvidas das pessoas que a perguntam diariamente a respeito da maternidade ou enfermaria de partos contígua à Casa de Saúde N. Sra. da Ajuda", afirmando que "em sua ausência, quem assiste às parturientes é a parteira Tygna. Além disso, ao aparecer algum caso perigoso é chamado o Dr Feijó". O comunicado fornece alguns detalhes da Casa de Saúde, em tom de propaganda, garantindo que "as pessoas que mandarem suas escravas para esta enfermaria podem certificar-se do tratamento, desvelos e atenções" e completa ao final que as mesmas serão tratadas com dedicação e atenção, da mesma forma como são tratadas as parturientes livres, pois "a caridade não conhece posições, nem é distintiva para o livre ou escravo." A parteira dizia ainda que "o estabelecimento tem salas para pessoas livres que não estando no caso de fazerem grandes despesas como costureiras, floristas, modistas ou qualquer outra artista nacional ou estrangeira para não recorrerem, entretanto, à Santa Casa de Misericórdia." ${ }^{55}$ Nessa mesma publicação, Durocher afirmou que quem não quisesse tratar no escritório do estabelecimento, que poderia fazê-lo em sua residência ou da parteira Tygna. Em 1863, deu-se o último anúncio encontrado em que se menciona Durocher como a parteira principal do estabelecimento, entretanto, as propagandas da Casa de Saúde continuaram até pelo menos 1885 , ainda com enfermaria de partos, porém, citando-se médicos parteiros e obstetras.

A Casa de Saúde Nossa Senhora da Glória, de acordo com anúncio publicado em 1862, ${ }^{56}$ apresentava uma maternidade e contava com quatro médicos parteiros. Na maternidade, os doutores Antônio Marcolino Fragoso, que também era diretor e proprietário da casa, e Domingos José Bernardino de Almeida eram parteiros efetivos. Já o dr. Luiz da Cunha Feijó e o dr. Francisco Ferreira de Abreu eram parteiros consultantes. Na maternidade, afirmava-se que haveria todo o cuidado e que havia uma enfermaria para criança, as quais, seriam "tratadas com todo o carinho". ${ }^{57}$ No anúncio citado não havia menção às parteiras atuantes na casa. No ano seguinte, em 1863, a maternidade da casa

\footnotetext{
${ }^{55}$ Diário do Rio de Janeiro, 19 de maio de 1863, p.3.

${ }^{56}$ Diário do Rio de Janeiro, 14 de dezembro de 1862, p.4.

${ }^{57}$ Diário do Rio de Janeiro, 14 de dezembro de 1862, p.4.
} 
passou a aceitar parteiras atuantes, porém, seriam autônomas, contratadas pelas famílias.

O anúncio novo apresentava de maneira detalhada as informações da Casa de Saúde, tanto a respeito dos funcionários como as características do espaço e serviços oferecidos. Na maternidade, dividiam-se as pacientes em $1^{\text {a }}$ classe, que eram livres e pagavam o valor mais alto e as de $2^{\mathrm{a}}$ classe, que eram escravas, cujo atendimento era mais barato. Para ambas, o valor era referente aos sete dias de diárias incluindo o parto. É interessante destacar que, apesar das informações contidas no anúncio, em 1863, a parteira Felicíssima Rosa Pereira Ferreira publicou um comunicado no Diário do Rio de Janeiro no qual confirmava o seu retorno à maternidade da casa de saúde do dr. Fragoso, após regresso de viagem à Europa.

Se compararmos os anúncios das maternidades criadas e dirigidas por parteiras com as maternidades das casas de saúde, podemos perceber que a diferença decorre da posição dada à parteira. Nas maternidades possuíam lugar de destaque, enquanto nas casas de saúde eram secundárias ou inexistentes. É importante destacar que algumas parteiras que trabalharam nesses estabelecimentos possuíam algum tipo relação ou contato prévio com médicos das casas de saúde. Isso pode ser verificado com a parteira Tygna e o dr. Feijó, diretor na Casa de Saúde Nossa Senhora da Glória, quando a mesma citou ter sido sua aluna..$^{58}$

Além disso, casas de saúde tiveram seu primeiro anúncio em periódico em 1863, enquanto as maternidades tiveram dez anos depois a sua primeira propaganda. Isso não significa que elas não atuassem antes desse período, mas que poderia haver restrições para a autorização do estabelecimento de maternidades dirigidas por parteiras. Um indício dessa restrição são as multas impostas às parteiras acusadas de possuírem em sua residência uma casa de partos ou maternidade, o que as levava a ter que recorrer contra o pagamento de multa.

Observamos também que as casas de saúde pouco se deslocaram durante seu funcionamento, diferente das parteiras, que se mudavam frequentemente. No entanto, ainda que se mudassem, as parteiras procuraram se manter próximas ao seu antigo endereço. São exemplos a madame Borgé, que mudou de casa três vezes na mesma rua, bem como a madame Daure, que também se mudou na mesma rua e, depois, para uma rua próxima, ${ }^{59}$ mantendo-se nas

\footnotetext{
${ }^{58}$ Diário do Rio de Janeiro, 7 de junho de 1864, p.4; 12 de junho de 1864, p.4; 19 de junho de 1864, p.4; 26 de junho de 1864, p.4.

${ }^{59}$ Almanaque Laemmert, 1871, p. 467; 1874, p. 586; 1879, p. 666; 1874, p. 586 e 1877, p. 709.
} 
redondezas. Cabe destacar que, ainda que essas parteiras tivessem se mudado para lugares pouco mais distantes em outros momentos, demonstrado em outros anúncios, isso não ocorreu quando se tratava das casas de maternidade anunciadas. Ou seja, sua casa enquanto casa de maternidade, manteve-se num endereço fixo ou nas proximidades do mesmo.

Outro ponto que chamou a atenção foi a distância entre uma casa de saúde e outra e o afastamento das mesmas da parte mais central da cidade. Já as parteiras, embora também não estivessem em uma região central da cidade, estavam numa parte mais próxima a ela, além de estarem perto também umas das outras. Verificamos que, as parteiras e suas maternidades continuavam a ser mais populares do que as casas de saúde que atendiam parturientes a julgar pelo número muito maior de anúncios das primeiras e do reduzido número de casas de saúde que ofereciam esse serviço. No entanto, entre 1882 e 1889, não foram encontrados mais anúncios das maternidades no Rio de Janeiro, o que pode sugerir a sua diminuição. Torna-se interessante, então, ampliar a pesquisa para compreender melhor esse dado. Devemos considerar também a legislação no que concerne à permissão para a abertura de casas de maternidade, pois, tornando-se mais rígida, menos parteiras poderiam apresentar esse tipo de serviço às suas clientes.

\section{À guisa de conclusão}

Os periódicos analisados em nosso trabalho, quais sejam Diário do Rio de Janeiro, Almanaque Laemmert, o Paquete do Rio, Correio Mercantil e O Despertador, oferecem um material rico que contribui para a análise de aspectos importantes relacionados às parteiras. Através dessas fontes, juntamente com documentação encontrada no Arquivo Geral do Rio de Janeiro, foi possível responder a algumas questões propostas nesse artigo.

Desse modo, vemos que, a partir da década de 1830, houve uma diversificação do perfil das mulheres que desempenhavam o ofício de parteira no Brasil. Tanto a formação das mulheres na Faculdade de Medicina do Rio de Janeiro, como a chegada de parteiras estrangeiras contribuíram para isso. Identificamos também, como tentativa de atrair clientes, a oferta de serviços além da parturição, assim como o surgimento de novos locais de atuação das parteiras, tais como consultórios de médicos e casas de saúde. A parteira poderia participar desses locais no caso de terem contato com médicos parteiros que as chamassem para trabalhar. Nesses espaços, elas ficavam em posição subalterna, sempre atuando em situações menos graves. Ao contrário, a casa de maternidade era o espaço de autonomia da parteira, pois, na maioria delas, 
não havia médicos homens e elas poderiam atuar tanto sozinhas como em companhia de outras parteiras.

Por fim, destacamos a interação entre as parteiras, sobretudo as com formação acadêmica, verificada através do compartilhamento de endereços. Assim, além dos laços construídos entre parturientes e parteiras, frequentemente apontados pela historiografia, ressaltamos aqui as relações profissionais e de amizade, ainda que não se possa ignorar a rivalidade e concorrência, entre as próprias parteiras que atuaram no Rio de Janeiro imperial.

Artigo recebido para publicação em 02/09/2016 Artigo aprovado para publicação em 04/11/2016 